\title{
(3) Intravitreal triamcinolone acetate for radiation OPEN ACCESS maculopathy recalcitrant to high-dose intravitreal bevacizumab
}

\author{
Richard I Kaplan, 1,2 Sonal S Chaugule, 1,2 Paul T Finger ${ }^{1,2}$
}

\begin{abstract}
'The New York Eye Cancer Center, New York, NY, USA ${ }^{2}$ Department of Ophthalmology, The New York Eye and Ear Infirmary of Mount Sinai, New York, NY, USA
\end{abstract}

Correspondence to Paul T Finger, The New York Eye Cancer Center, New York City, NY, 10065, USA; pfinger@ eyecancer.com

Received 8 February 2017 Revised 16 March 2017 Accepted 19 March 2017 Published Online First 17 April 2017

\section{CrossMark}

To cite: Kaplan RI, Chaugule SS, Finger PT. $\mathrm{Br} J$ Ophthalmol 2017:101:1694-1698.

\begin{abstract}
Background/aims To evaluate the effect of adjuvant intravitreal triamcinolone acetonide (ITA) for radiation maculopathy (RM) recalcitrant to high-dose bevacizumab in patients with choroidal melanoma after plaque radiotherapy.

Methods Eight eyes of eight patients with RM secondary to plaque radiotherapy for choroidal melanoma, recalcitrant to high-dose bevacizumab $(3.0 \mathrm{mg}$ ) were retrospectively evaluated. Intravitreal injections of ITA $(4 \mathrm{mg} / 0.1 \mathrm{~mL})$ were performed at 4-week to 16-week intervals as an adjunct to continued bevacizumab therapy. Change in central foveal thickness (CFT) as measured by optical coherence tomography and change in visual acuity (VA) were the main outcome measures.

Results At the time of diagnosis of choroidal melanoma, VA was $20 / 20$ to $20 / 50$ in $88 \%(n=7)$ and $20 / 60$ to $20 / 200$ in $12 \%(n=1)$. The mean radiation dose to the fovea was $81 \mathrm{~Gy}$ (median $75.2 \mathrm{~Gy}$; range: 22.72-132.8 Gy). The mean onset to RM was 25 months after plaque therapy (median 25 months; range 12-44 months). At the time of initiation of ITA, VA was 20/20 to $20 / 50$ in $38 \%(3 / 8)$, and $20 / 60$ to $20 / 200$ in $62 \%$ (5/8). After initiation of ITA, VA was stable or improved in $100 \%$ of patients ( $n=8)$ at 3 months, $88 \%$ at 6 months, $88 \%$ at 9 months and $75 \%$ at 12 months. Mean CFT was $417 \mu \mathrm{m}$ at ITA initiation, $339 \mu \mathrm{m}$ at 1 month, $355 \mu \mathrm{m}$ at 6 months, $339 \mu \mathrm{m}$ at 9 months and $359 \mu \mathrm{m}$ at 1 year. Conclusion Intravitreal triamcinolone can be added to preserve vision and decrease macular oedema in patients with RM recalcitrant to high-dose anti-vascular endothelial growth factor agents.
\end{abstract}

\section{INTRODUCTION}

Radiation maculopathy (RM) is the most common cause of irreversible vision loss in patients treated with plaque or charged particle radiotherapy for choroidal melanoma. ${ }^{1-4}$ The risk of RM has been related to total radiation dose, dose rate, the presence of synchronous systemic disease and radiation sensitisers. ${ }^{5-7}$ Signs of RM are similar to diabetic retinopathy including oedema, exudates, haemorrhages, cotton wool spots and capillary non-perfusion. $^{2} 8$ Radiation-related vision loss can be devastating, resulting in visual acuity (VA) worse than $20 / 200$ in as many as $43 \%$ of patients at 5 years and $68 \%$ of patients at 10 years after plaque therapy. $^{9}$

Treatment for RM has been challenging. Initially, laser photocoagulation was used to treat
RM with varying degrees of success. ${ }^{4}$ Periocular and intravitreal steroids have also been used to prevent and treat RM-associated macular oedema. ${ }^{10} 11$ However, the most lasting success has been attributed to the use of periodic, intravitreal anti-vascular endothelial growth factor (VEGF) medications. ${ }^{12-14}$ In 2016, Finger et al reported that escalating doses of intravitreal anti-VEGF therapy (bevacizumab, ranibizumab) preserved vision (within two lines of their initial VA) for $80 \%$ of patients for a mean 38 months (range 6-108). ${ }^{6} 15$

Investigators have explored polypharmacy for RM. Seibel et al ${ }^{13}$ demonstrated no difference in VA or central foveal thickness (CFT) when comparing treatment with intravitreal bevacizumab (IVB), solid dexamethasone and aqueous triamcinolone acetonide (ITA). In cases recalcitrant to anti-VEGF agents, reports have shown success in maintaining VA by using dexamethasone implant. ${ }^{16}$ Shah et $a l^{17}$ recently presented a case series of RM recalcitrant to low dose IVB (1.25 mg) successfully stabilised with ITA.

However, despite suppressing RM and maintaining vision with escalating doses of IVA as high as $3.0 \mathrm{mg}$, there developed a subset of recalcitrant cases. This study evaluated the efficacy of periodic adjunctive intravitreal steroid therapy in patients with RM recalcitrant to high-dose IVB injections.

\section{PATIENTS AND METHODS}

This study adhered to the tenets of the Declaration of Helsinki and the Health Insurance Portability and Privacy Act of 1996 and was approved by the Institutional Review Board of The New York Eye Cancer Center. Data for all patients with the diagnosis of uveal melanoma treated with palladium-103 $\left({ }^{103} \mathrm{Pd}\right)$ or iodine-125 $\left({ }^{125} \mathrm{I}\right)$ plaque radiotherapy and that subsequently received both anti-VEGF intravitreal injections and ITA between 2005 and 2016 were retrospectively reviewed. Of these, we found that our first ITA patient was treated in 2014.

\section{RISKS AND BENEFITS}

As part of informed consent, risks related to intravitreal steroid injection were discussed with patients including cataract, steroid-induced glaucoma, retinal detachment and endophthalmitis. The potential benefit of vision preservation was discussed within the framework of prior intravitreal steroid studies. 


\section{ITA ENTRY CRITERIA}

Only patients who were failing maximal IVB therapy were included in this study. Treatment failure (for both IVB and ITA) was defined as deteriorating VA or worsening clinical features (optical coherence tomography (OCT), VA or fluorescein angiography (FA)) on two consecutive monthly examinations despite maximum IVB $(3.0 \mathrm{mg})$.

Patients with follow-up of at least 1 year after starting ITA were included. Patient characteristics collected included age, race and medical problems. Best-corrected ETDRS (Early Treatment Diabetic Retinopathy Study) VA (in standardised examination rooms) was recorded at the time of diagnosis and at each examination thereafter. Tumour data included largest basal diameter, largest thickness and tumour proximity to optic nerve and fovea. Radiation data included total radiation dose (Gray) to the tumour apex, optic disc and fovea. Follow-up examinations were performed at 3-month to 4-month intervals until RM was diagnosed and then every 4 weeks for treatment. In addition to clinical examination, fundus photography, and/or FA, and CFT on OCT using the Spectralis OCT2 Module (Heidelberg Engineering, Heidelberg, Germany) were regularly performed at follow-up visits. RM was defined as macular haemorrhages, cotton-wool spots, microaneurysms or progressive macular oedema.

\section{METHODS OF INTRAVITREAL INJECTION}

Methods of intravitreal injection (aseptic technique) have evolved. Currently, we anaesthetise with a drop of topical proparacaine followed by betadine 5\%. After $30 \mathrm{~s}$, these are followed by two additional drops of topical viscous lidocaine applied 2 to 5 min apart. Lastly, an additional drop of betadine $5 \%$ is placed $30 \mathrm{~s}$ prior to injection. To minimise secondary corneal abrasions, eyelid speculums are only used for those who could not allow digital retraction. In this series, intravitreal injections were introduced at an angle through the pars plana using a $30 \mathrm{G}$ needle. ${ }^{18}$ Optic nerve perfusion and VA were normalised prior to discharge.

The ITA injection protocol is as described above with $4.0 \mathrm{mg} / 0.1 \mathrm{~mL}$ triamcinolone acetonide (preservative-free formulation). Injections of $3.0 \mathrm{mg}$ IVB were continued every 4 weeks, with ITA every 8 to 12 weeks, modulated based on changes in $\mathrm{VA}$ and clinical features.

\section{RESULTS}

Here we report on eight eyes with RM recalcitrant to high-dose IVB (table 1). Their ophthalmic findings and radiation treatment parameters (at diagnosis) are listed (table 2). In sum, their mean

${ }^{103} \mathrm{Pd}$ radiation doses to the apex and fovea were $69 \mathrm{~Gy}$ and 82

\begin{tabular}{ll}
\hline Table 1 Demographic characteristics & \\
\hline $\begin{array}{l}\text { Age (years) } \\
\quad \text { Mean (range) }\end{array}$ & $70(47-90)$ \\
\hline Sex & $2(25)$ \\
$\quad$ Male & $6(75)$ \\
\hline Female & \\
Eye & $6(75)$ \\
$\quad$ Right & $2(25)$ \\
\hline Left & \\
Systemic disease & $2(25)$ \\
\hline Diabetes mellitus & $3(38)$ \\
\hline Hypertension &
\end{tabular}

Table 2 Choroidal melanoma characteristics, plaque radiotherapy parameters and initial RM treatment

\begin{tabular}{|c|c|}
\hline \multicolumn{2}{|l|}{ Visual acuity prior to plaque, $\mathrm{n}(\%)$} \\
\hline $20 / 20$ to $20 / 50$ (logMAR 0 to 0.4$)$ & $7(88)$ \\
\hline $20 / 60$ to $20 / 200$ (logMAR 0.5 to 1 ) & $1(12)$ \\
\hline \multicolumn{2}{|l|}{ Tumour size: mean (median, range) } \\
\hline Basal dimension & $11.1(11.9,7.1-13.9)$ \\
\hline Thickness & $4.3(2.8,2.3-10.9)$ \\
\hline Proximity to optic disc & $3.2(2.5,0.5-9.4)$ \\
\hline Proximity to fovea & $1.8(1.5,0-5.7)$ \\
\hline \multicolumn{2}{|l|}{ Isotope: mean (\%) } \\
\hline Palladium-103 & $7(88)$ \\
\hline lodine-125 & $1(12)$ \\
\hline \multicolumn{2}{|l|}{ Mean radiation dose, Gy: mean (median, range) } \\
\hline Apex & $69.4(70.2,48.2-87.4)$ \\
\hline Optic disc & $56.2(9.0-125.1)$ \\
\hline Fovea & $81.5(75.2,22.7-138.2)$ \\
\hline AJCC stage: stage (n) & $\mathrm{T} 1(4), \mathrm{T} 2(2), \mathrm{T} 3(2)$ \\
\hline Months to onset of RM: mean (median, range) & $26(25,12-44)$ \\
\hline
\end{tabular}

AJCC, American Joint Committee on Cancer; RM, radiation maculopathy.

Gy, respectively. The mean onset to RM was 25 months after plaque therapy.

Their initial RM treatment is summarised in table 3. Dose escalations (IVB) prior to the introduction of ITA were defined as increased dose in milligrams or shortened intervals between doses. With that definition, $88 \%(\mathrm{n}=7)$ of patients had received four escalations of IVB dose and $12 \%(n=1)$ received five escalations. The mean duration of anti-VEGF therapy prior to initiation of ITA was 55 months. In all cases, anti-VEGF therapy had been escalated to $3.0 \mathrm{mg}$ of monthly IVA prior to the initiation of ITA. There had been a mean number of 10 injections at this dose over mean duration of 6 months prior to polypharmacy with ITA. After introduction of ITA, mean number of ITA injections was 7 (range 3-11) and mean follow-up period was 21 months (range 15-28).

One patient was deemed an ITA non-responder, showing no improvement in VA and progressively increasing CFT after 3 monthly ITA injections. ITA was discontinued and the patient received focal laser on the next visit. Despite all interventions, her vision and CFT progressively deteriorated.

\begin{tabular}{|c|c|}
\hline \multicolumn{2}{|l|}{ Prior to ITA initiation } \\
\hline \multicolumn{2}{|l|}{ No of IVB injections } \\
\hline $1.25 \mathrm{mg}(\mathrm{n}=8)$ & $16(16,2-35)$ \\
\hline $2.0 \mathrm{mg}(\mathrm{n}=6)$ & $7(5,3-15)$ \\
\hline $2.5 \mathrm{mg}(\mathrm{n}=7)$ & $16(12,3-35)$ \\
\hline $3.0 \mathrm{mg}(\mathrm{n}=8)$ & $10(9,1-19)$ \\
\hline IOP (mm Hg) & $12(12,10-18)$ \\
\hline \multicolumn{2}{|l|}{ After ITA initiation } \\
\hline No of ITA injections & $7(7,3-11)$ \\
\hline No of IVB injections & $20(20,14-27)$ \\
\hline IOP & $12(12,9-19)$ \\
\hline Months of follow-up & $21(21,15-28)$ \\
\hline
\end{tabular}

All values listed as mean (median, range).

IOP, intraocular pressure; ITA, intravitreal triamcinolone acetonide; IVB, intravitreal bevacizumab. 
Table 4 Clinical details

\begin{tabular}{|c|c|c|c|c|c|c|c|c|}
\hline & \multicolumn{8}{|c|}{ Months of follow-up after ITA initiation } \\
\hline & $0(n=8)$ & $1(n=8)$ & $3(n=8)$ & $6(n=8)$ & $9(n=8)$ & $12(n=8)$ & $18(n=4)$ & $24(n=3)$ \\
\hline VA mean, logMAR & 0.53 & 0.51 & 0.47 & 0.50 & 0.52 & 0.59 & 0.63 & 0.54 \\
\hline \multicolumn{9}{|c|}{ VA change by $\geq 2$ lines } \\
\hline Improved, n (\%) & NA & 0 & 0 & 0 & $2(25)$ & $2(25)$ & 0 & 0 \\
\hline Stable, $\mathrm{n}(\%)$ & NA & $8(100)$ & $8(100)$ & $7(88)$ & $5(62)$ & $4(50)$ & $3(75)$ & $2(67)$ \\
\hline Worse, $\mathrm{n}(\%)$ & NA & 0 & 0 & $1(12)$ & $1(12)$ & $2(25)$ & $1(25)$ & $1(33)$ \\
\hline $\mathrm{CFT}_{,} \mu \mathrm{m}$ & 417 & 339 & 377 & 356 & 339 & 357 & 548 & 609 \\
\hline
\end{tabular}

CFT, central foveal thickness; ITA, intravitreal triamcinolone acetonide; VA, visual acuity.

\section{CENTRAL FOVEAL THICKNESS}

Decreased CFT by optical coherence tomography was noted in $88 \%(n=7)$ of patients at 12 months (table 4 , figure 1$)$. At 18 $(n=4)$ and $24(n=3)$ months, CFT remained reduced from ITA initiation in $75 \%$ and $67 \%$ of patients, respectively. A representative case is shown in figure 2 . The aforementioned ITA non-responder $(\mathrm{n}=1)$ experienced $55 \%, 112 \%$ and $87 \%$ increases in CFT at 12,18 and 24 months, respectively.

\section{VISUAL ACUITY}

A significant change in VA was defined as a gain or loss of two ETDRS lines of vision. Resultant VA within two ETDRS lines of their ITA-entry initial VA was measured in $100 \%$ of patients $(n=8)$ at 3 months, $88 \%$ of patients at 6 months, $88 \%$ of patients at 9 months and $75 \%$ of patients at 12 months (table 4 , figure 3 ). Of these, $29 \%$ and 33\% $(n=2)$ had improved by at least two lines at 9 and 12 months, respectively. At 18 months, 75\% (n=3) remained within two lines of their initial VA, while $25 \%(n=1)$ worsened. At 24 months, $67 \%(n=2)$ remained within two lines of their initial VA, while $33 \%(n=1)$ worsened. It is important to note that this one failure was a significant outlier that affected the mean VA outcome (her vision decreased from 20/100 to $20 / 650$ at 12 months).

\section{COMPLICATIONS}

In this study, two patients (25\%) developed medication-related ocular hypertension. In both cases, intraocular pressure returned to pre-ITA levels with topical therapy alone. One patient (12\%) developed advancement of cataract requiring extraction. There were no cases of endophthalmitis or retinal detachment.

\section{DISCUSSION}

In this series, ITA was found to be a safe and promising treatment for RM recalcitrant to high-dose periodic anti-VEGF therapy. Stabilisation or improvement of vision was achieved for $100 \%$ of patients at 3 months, $88 \%$ of patients at 9 months, and $75 \%$ of patients at 12 months. Decreased CFT on OCT was achieved in $75 \%$ of patients at months 1 to 6 and for $88 \%$ at 12 months. These findings stand in stark contrast to our findings at the initiation of ITA, where all patients were receiving bevacizumab $3.0 \mathrm{mg}$ at 4 -week intervals with worsening CFTs or VA on two consecutive visits.

\section{LASER, VEGF AND RM}

Uveal melanomas and their chronic exudative retinal detachments produce VEGF. ${ }^{19}$ Then, radiation induces ocular ischaemic tissue that, in turn, produces VEGF. Laser photocoagulation was first used to treat RM and neovascular glaucoma. Though antiVEGF drugs had not been discovered at the time, Finger, Hykin, Materin and others unknowingly achieved an anti-VEGF effect by directly treating radiation-induced chorioretinal ischaemia and by laser demarcation (devitalisation of posterior uveal melanomas). ${ }^{4021}$ Though it is less likely to effect a permanent cure, laser is still used as a single RM treatment alternative to longterm periodic intravitreal injections.

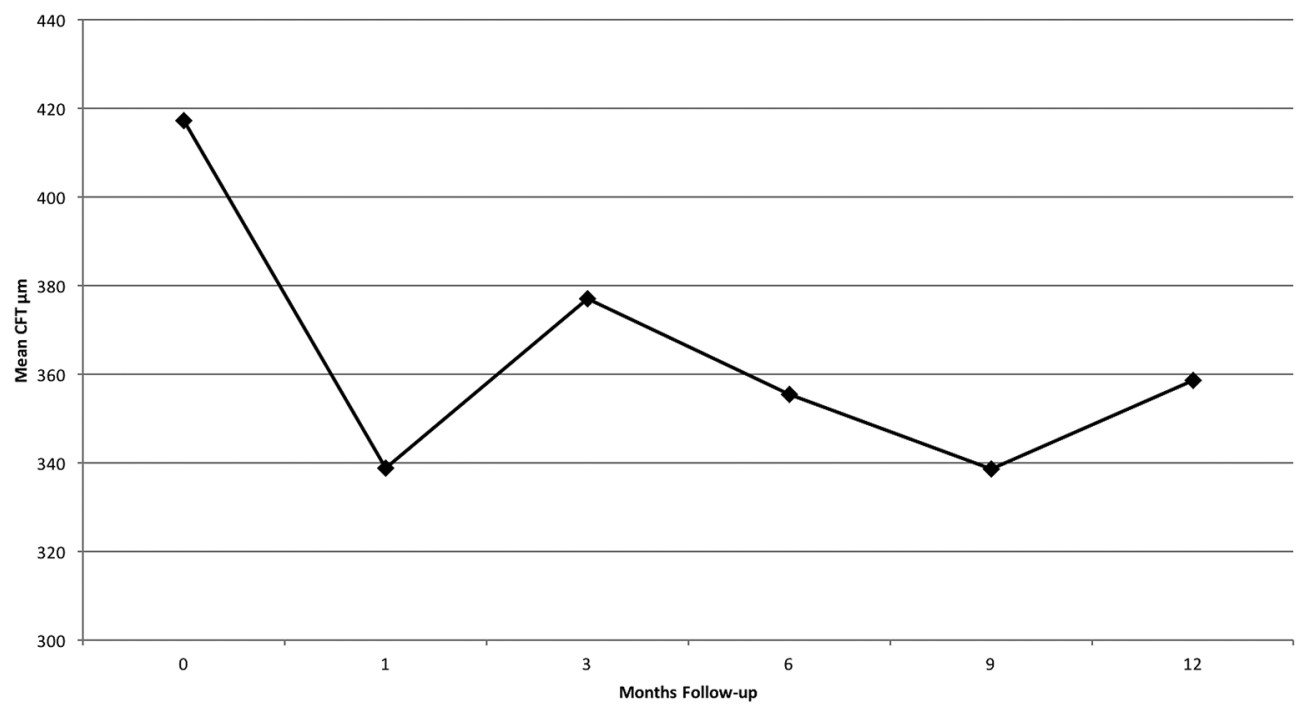

Figure 1 Mean central foveal thickness (CFT) in micrometre as measured by optical coherence tomography (OCT). The line graph depicts all patients $(n=8)$ receiving intravitreal triamcinolone acetate for radiation maculopathy recalcitrant to high-dose intravitreal bevacizumab over time. 


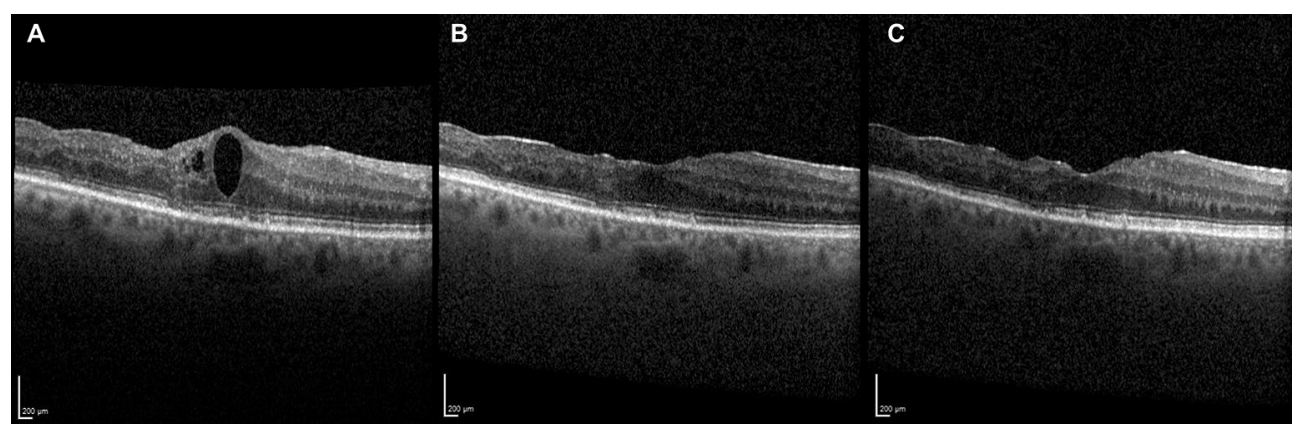

Figure 2 A 75-year-old woman with radiation maculopathy recalcitrant to high-dose intravitreal bevacizumab was treated with adjunctive intravitreal triamcinolone acetonide. Resolution of macular oedema as demonstrated by optical coherence tomography at the time of initiation (A) was sustained after 12 months (B) and 18 months (C) of follow-up.

\section{Steroids for RM}

Radiation retinopathy exhibits a vaso-occlusive, vasoproliferative pathophysiology similar to diabetic retinopathy; they are both progressive and respond to anti-VEGF and anti-inflammatory therapies. For RM, anti-VEGF therapy has been shown to reduce macular oedema by reducing vascular permeability and the formation of new blood vessels by direct inhibition of the inflammatory cytokine VEGF. ${ }^{12}$ However, IVB has been associated with an increase of other intraocular cytokines, such as interleukin 8 (IL-8). ${ }^{22}$ In contrast, ITA's anticytokine properties are thought to reduce the expression of hypoxia-induced VEGF. $^{23}$ Another proposed mechanism of ITA is restoring the integrity of the inner retinal barrier by increasing tight junction proteins and thereby reducing vascular leakage. ${ }^{24}$ Finally, by upregulating adenosine, triamcinolone has been shown to reduce osmotic swelling of Muller cells. Jeon et $\mathrm{al}^{25}$ demonstrated ITA's efficacy in managing diabetic macular oedema recalcitrant to IVB; they related elevated aqueous IL-8 levels to efficacy. These anti-inflammatory properties make ITA a promising adjunctive therapy for RM.

Seibel, Horgan and Shields' clinical research on steroid therapy for RM suggest temporary improvement in radiation retinopathy. ${ }^{101113}$ However, none of these efforts suggested or employed continuous periodic treatment. In contrast, our study showed that when ITA is used together with IVB, there is an additive effect. We suspect that cessation of ITA in our subset of recalcitrant cases would similarly lead to deterioration in functional and structural outcomes.

\section{PRIOR ITA STUDIES}

Shah et al $^{17}$ presented 25 patients who had received ITA $4 \mathrm{mg}$ in addition to $1.25 \mathrm{mg}$ bevacizumab for either severe RM or RM refractory to IVB monotherapy. In that study, severity was based on macular oedema demonstrated on OCT and refractory was defined as minimal improvement in oedema after three injections. They found stability in mean VA and modest improvement in mean foveal thickness. It is unclear from the study how many patients were refractory to IVB at the initiation of ITA and a substantial percentage may have received ITA for severity alone. ITA was initiated after a mean of 23.7 months after RM was diagnosed, at a shorter duration than our study.

Horgan et $a l^{10}$ presented 55 patients with choroidal melanoma who were treated with primary $40 \mathrm{mg}$ periocular triamcinolone at plaque application and again 4 and 8 months later,

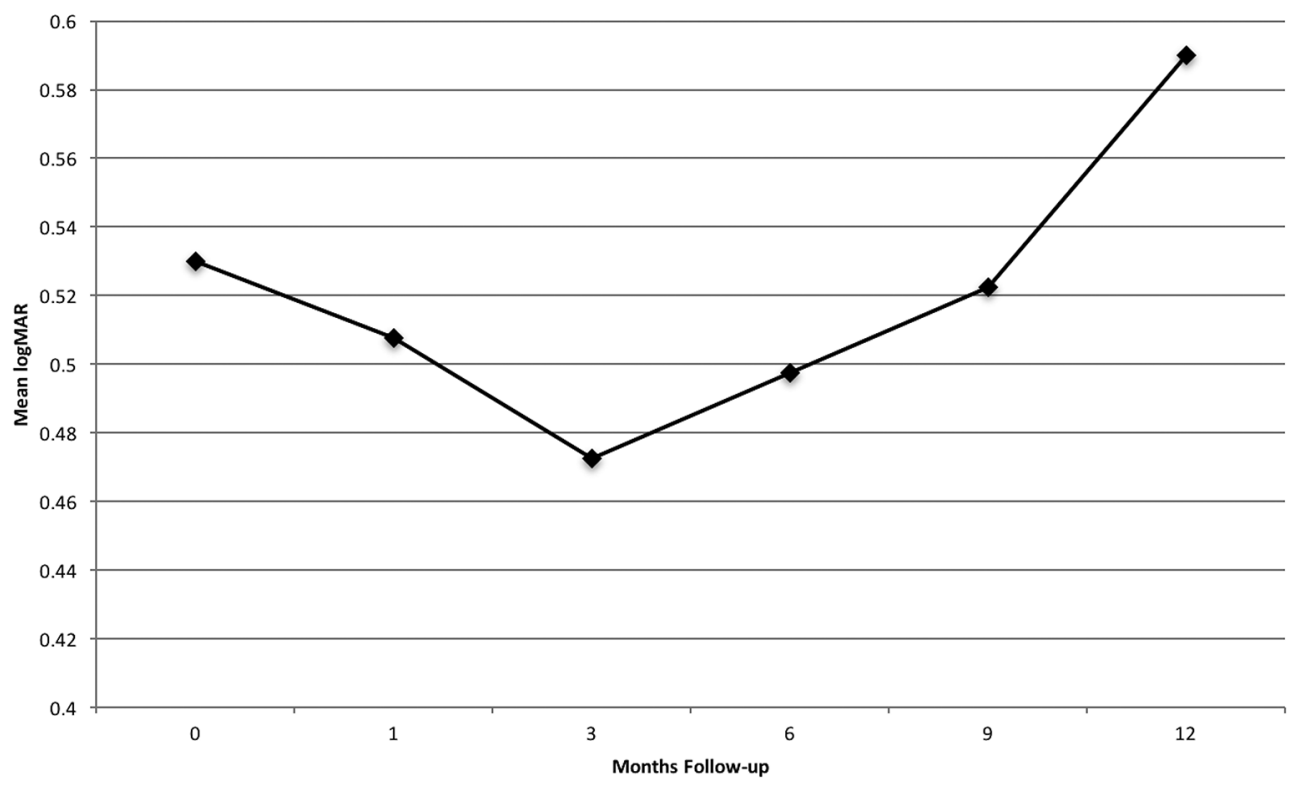

Figure 3 Mean visual acuity (logMAR, converted from ETDRS acuity) in all patients $(n=8)$ whom received intravitreal triamcinolone acetate for radiation maculopathy recalcitrant to high-dose intravitreal bevacizumab. ETDRS, Early Treatment Diabetic Retinopathy Study. 
with 24 months of follow-up. Patients in the intervention group had a reduced risk of macular oedema. However, there was a similar rate of moderate and severe vision loss between the intervention and control groups. Shields et $a l^{11}$ also presented 31 patients with RM secondary to plaque therapy prospectively treated with primary ITA. They found that while 91\% of patients' vision stabilised or improved at 1 month, this percentage declined to $45 \%$ at an endpoint of 6 months. In contrast, our study found a similar effect at 1 month and a substantially higher percentage of patients with stable or improved VA at 6 months. These studies differ from ours in many ways; most importantly, in both studies patients were naive to prior RM treatments (including anti-VEGF therapy) and in the latter received only one ITA injection.

\section{INTRAVITREAL IVB}

Our experience with the long-term management of patients with RM found escalating doses of anti-VEGF are needed in most patients to maintain the functional and architectural benefit. ${ }^{15}$ This experience suggests that treated RM is progressive, much like treated hypertension or diabetes. In response to signs of RM progression, all the patients in this study had been given what we considered to be maximum doses of IVB. This approach is supported by prior studies showing that high-dose bevacizumab achieves increased concentrations in the vitreous, and that improvement can be achieved with highdose ranibizumab for patients who fail lower dose therapy. ${ }^{2627}$

This study also differs from Shah in that we only treated recalcitrant cases. ${ }^{17}$ Therefore, there was an extended time interval between the onset of RM and the initiation of ITA. Further, cases that had only failed low dose anti-VEGF therapy may have improved with higher doses and were thus not necessarily recalcitrant.

ITA has been associated with increased intraocular pressure, glaucoma and cataract in as many as half of patients after 1 year of therapy. ${ }^{28}$ In this study, two patients required topical glaucoma medications and one patient was referred for cataract surgery. While these complications should be considered before initiation of ITA, we have found that they are outweighed by the benefit of preserving vision in patients with no alternative. One patient failed to respond to ITA, and their significant effect on the mean CFT and VA results in this study should be noted. Limitations of our study include its retrospective nature and small sample size. It is possible that with a larger sample size more complications and treatment failures would be discovered. However, our study shows that ITA, added to high-dose IVB, can be used to preserve vision and decrease macular oedema in patients with RM recalcitrant to high-dose anti-VEGF agents. Larger, prospective, registry and confirmatory studies with longer follow-up and differing dose regimens should be performed.

Contributors PTF, SSC and RIK involved in conception and design, data interpretation, drafting the article and final approval of the version to be published. SSC and RIK involved in data acquisition.

Funding This work was supported byThe Eye Cancer Foundation.

Competing interests PTF was awarded and owns a US Patent no 7553486 titled 'Anti-VEGF Treatment for Radiation Induced Vasculopathy'.

Ethics approval Institutional Review Board and Ethics Committees of The New York Eye Cancer Center.

Provenance and peer review Not commissioned; externally peer reviewed.

Open Access This is an Open Access article distributed in accordance with the Creative Commons Attribution Non Commercial (CC BY-NC 4.0) license, which permits others to distribute, remix, adapt, build upon this work non-commercially, and license their derivative works on different terms, provided the original work is properly cited and the use is non-commercial. See: http://creativecommons.org/ licenses/by-nc/4.0/

(c) Article author(s) (or their employer(s) unless otherwise stated in the text of the article) 2017. All rights reserved. No commercial use is permitted unless otherwise expressly granted.

\section{REFERENCES}

1 Gliedman PR, Steinfeld AD. Radiation retinopathy. JAMA 1987:257:780.

2 Brown GC, Shields JA, Sanborn G, et al. Radiation retinopathy. Ophthalmology 1982:89:1494-501

3 Finger PT, Chin KJ, Duvall G, et al; Palladium-103 for Choroidal Melanoma Study Group. Palladium-103 ophthalmic plaque radiation therapy for choroidal melanoma: 400 treated patients. Ophthalmology 2009;116:790-6.

4 Finger PT, Kurli M. Laser photocoagulation for radiation retinopathy after ophthalmic plaque radiation therapy. Br J Ophthalmol 2005;89:730-8.

5 Finger PT. Tumour location affects the incidence of cataract and retinopathy after ophthalmic plaque radiation therapy. Br J Ophthalmol 2000;84:1068-70.

6 Finger PT, Chin KJ. Intravitreous ranibizumab (lucentis) for radiation maculopathy. Arch Ophthalmol 2010;128:249-52.

7 Finger PT, Chin KJ, Yu GP, et al; Palladium-103 for Choroidal Melanoma Study Group. Risk factors for radiation maculopathy after ophthalmic plaque radiation for choroidal melanoma. Am J Ophthalmol 2010;149:608-15.

8 Amoaku WM, Archer DB. Fluorescein angiographic features, natural course and treatment of radiation retinopathy. Eye 1990;4(Pt 5):657-67.

9 American Brachytherapy Society - Ophthalmic Oncology Task Force. Electronic address: paulfinger@eyecancer.com, ABS - OOTF Committee. The American Brachytherapy Society consensus guidelines for plaque brachytherapy of uveal melanoma and retinoblastoma. Brachytherapy 2014;13:1-14.

10 Horgan N, Shields CL, Mashayekhi A, et al. Periocular triamcinolone for prevention of macular edema after iodine 125 plaque radiotherapy of uveal melanoma. Retina 2008;28:987-95

11 Shields CL, Demirci H, Dai V, et al. Intravitreal triamcinolone acetonide for radiation maculopathy after plaque radiotherapy for choroidal melanoma. Retina 2005; 25:868-74

12 Finger PT, Chin K. Anti-vascular endothelial growth factor bevacizumab (avastin) for radiation retinopathy. Arch Ophthalmol 2007;125:751-6.

13 Seibel I, Hager A, Riechardt Al, et al. Antiangiogenic or corticosteroid treatment in patients with radiation maculopathy after proton beam therapy for uveal melanoma. Am J Ophthalmol 2016:168:31-9.

14 Shah NV, Houston SK, Markoe AM, et al. Early SD-OCT diagnosis followed by prompt treatment of radiation maculopathy using intravitreal bevacizumab maintains functional visual acuity. Clin Ophthalmol 2012;6:1739-48.

15 Finger PT, Chin KJ, Semenova EA. Intravitreal anti-VEGF therapy for macular radiation retinopathy: a 10-year study. Eur J Ophthalmol 2016;26:60-6.

16 Bui KM, Chow CC, Mieler WF. Treatment of recalcitrant radiation maculopathy using intravitreal dexamethasone (Ozurdex) implant. Retin Cases Brief Rep 2014;8:167-70.

17 Shah NV, Houston SK, Markoe A, et al. Combination therapy with triamcinolone acetonide and bevacizumab for the treatment of severe radiation maculopathy in patients with posterior uveal melanoma. Clin Ophthalmol 2013;7:1877-82.

18 Mehta MC, Finger PT. Angled transscleral intravitreal injection: a crossover study. Eur J Ophthalmol 2015;25:173-6.

19 Yang M, Kuang X, Pan Y, et al. Clinicopathological characteristics of vascular endothelial growth factor expression in uveal melanoma: a meta-analysis. Mol Clin Oncol 2014;2:363-8.

20 Materin MA, Bianciotto CG, Wu C, et al. Sector laser photocoagulation for the prevention of macular edema after plaque radiotherapy for uveal melanoma: a pilot study. Retina 2012:32:1601-7.

21 Hykin PG, Shields CL, Shields JA, et al. The efficacy of focal laser therapy in radiationinduced macular edema. Ophthalmology 1998;105:1425-9.

22 Forooghian F, Kertes PJ, Eng KT, et al. Alterations in the intraocular cytokine milieu after intravitreal bevacizumab. Invest Ophthalmol Vis Sci 2010;51:2388-92.

23 Zhang X, Wang N, Schachat AP, et al. Glucocorticoids: structure, signaling and molecular mechanisms in the treatment of diabetic retinopathy and diabetic macular edema. Curr Mol Med 2014:14:376-84.

24 Gillies MC. Regulators of vascular permeability: potential sites for intervention in the treatment of macular edema. Doc Ophthalmol 1999;97:251-60.

25 Jeon S, Lee WK. Effect of intravitreal triamcinolone in diabetic macular edema unresponsive to intravitreal bevacizumab. Retina 2014;34:1606-11.

26 Meyer CH, Krohne TU, Holz FG. Intraocular pharmacokinetics after a single intravitreal injection of $1.5 \mathrm{mg}$ versus $3.0 \mathrm{mg}$ of bevacizumab in humans. Retina 2011:31:1877-84.

27 Finger PT, Chin KJ. High-dose $(2.0 \mathrm{mg})$ intravitreal ranibizumab for recalcitrant radiation retinopathy. Eur I Ophthalmol 2013;23:850-6.

28 Yilmaz T, Weaver CD, Gallagher MJ, et al. Intravitreal triamcinolone acetonide injection for treatment of refractory diabetic macular edema: a systematic review. Ophthalmology 2009;116:902-13. 